\title{
Effect of molding technology and porosity on explosive combustion
}

\author{
Hong-Bin Li ${ }^{1}$, Jian Yang ${ }^{2}$, Peng-Gang $\mathrm{Jin}^{3}$ \\ Xi'an Modern Chemistry Research Institute, Xi'an 710065, China \\ ${ }^{3}$ Corresponding author \\ E-mail: 1ihongbin6868@163.com, ${ }^{2}$ yangjian@163.com, ${ }^{3}$ jnjfv77@163.com
}

Received 16 July 2020; accepted 31 July 2020

DOI https://doi.org/10.21595/vp.2020.21599

Check for updates

Copyright $(2020$ Hong-Bin Li, et al. This is an open access article distributed under the Creative Commons Attribution License, which permits unrestricted use, distribution, and reproduction in any medium, provided the original work is properly cited.

\begin{abstract}
In order to understand the reaction growth characteristics and its influencing factors of typical explosives after non-impact ignition, a device and method for studying the reaction growth characteristics of explosives after non-impact ignition were established. The effects of explosive composition, forming process and porosity on the reaction growth after ignition were studied by this method. The research on ZY-5 explosive shows that the change of explosive composition can significantly affect the reaction state of explosive after ignition. The microstructure of combustion products is studied by scanning electron microscopy. It is considered that the bonding and combustion products of hydroxyl-butadiene system used in pouring explosive construct a space network with flame retardant function, which plays a very good role in flame retardant. Inhibition.
\end{abstract}

Keywords: explosive, explosion, combustion, DDT.

\section{Introduction}

Explosive is an autocatalytic substance, its chemical reaction is self-sustaining, and the reaction is difficult to control. The non-impact ignition mechanism and ignition threshold of explosives are one of the main contents of the safety design of explosives [1-4]. Whether the explosives grow into combustion or detonation after ignition depends on the competition between the reaction heat release of explosives and the heat release to the surrounding environment. Blaine W. Asay et al. Reviewed the literature on explosive combustion. From the perspective of basic theory, experimental research and numerical calculation, the research progress and future development trend of explosive combustion are described comprehensively and systematically [5]. Lawrence Livermore National Laboratory, J. L. Maienschein, J. F. Wardell researched the deflagration behavior of PBXN-I09 and composition B at high pressures and temperatures; The results show that $\mathrm{PBXN-I09}$ and explosive $\mathrm{B}$ have a wide range of combustion characteristics. With the increase of pressure, the combustion rate pressure exponent of PBXN-I09 increases first and then decreases. The experimental results show that PBXN-I09 is superior to B explosive in combustion to detonation transition [6]. Turkey S. Ctirdaneli et al. Studied the high-pressure combustion performance of propellant by using high-pressure combustion device of propellant. The test device and test method also have reference significance for explosives [7]. Normally, the results show that the burning rate decreases with the increase of charge density. When the charge density is low, the pores between the explosive particles increase, which is conducive to the deep penetration of gas products into the explosive, so as to increase the combustion area and the burning rate. The numerical calculation technology of explosive combustion has also been greatly developed, at present, it has preliminary engineering application value $[8,9]$. In this paper, the experimental equipment and method of explosive ignition and combustion are established. The combustion propagation speed and reaction zone temperature of explosive are obtained by using ultra-fine thermocouple. The influence of molding technology and density on the combustion characteristics of typical explosive is further studied. 


\section{Experiment}

\subsection{Samples and instruments}

Measuring cylinder, Vernier caliper, Electronic balance, Ultra-fine thermocouple, Igniter, Alcohol and absorbent cotton.

High speed photography: 5000 FPS.

Paperless recorder, monitoring equipment, computer.

\subsection{Experiment layout}

The experimental layout is shown in Fig. 1. The test results are mainly from three aspects, field observation, camera recording and thermocouple data. The calculation formula of burning rate is as follows [10]:

$u=\frac{s}{t}$

where $u$ is the burning rate, $\mathrm{mm} / \mathrm{s} ; s$ is the distance, $\mathrm{mm}$; $t$ is the time, $\mathrm{s}$; taking the time when the thermocouple temperature reaches $30^{\circ} \mathrm{C}$ as the starting point to record the data [11].

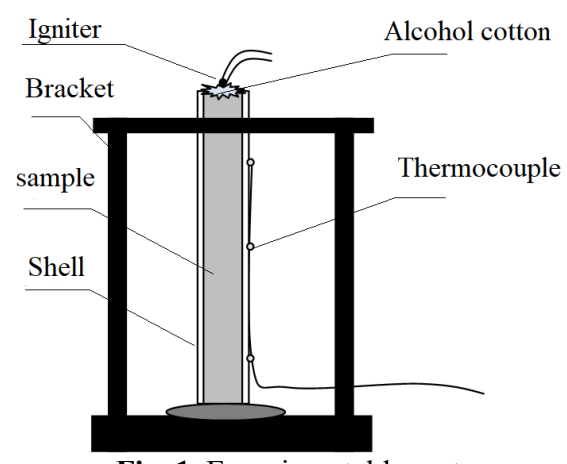

Fig. 1. Experimental layout

\section{Experimental results and discussion}

\subsection{Influence of molding technology on the ignition growth of explosives}

The ignition and combustion properties of typical molding powder, TNT, pouring explosive and melting explosive were studied. The sample parameters are shown in Table 1, the experimental results are shown in Table 2, and the photos of combustion products are shown in Fig. 2.

Table 1. Sample parameters

\begin{tabular}{|c|c|c|c|c|}
\hline No. & Molding technology & Explosives & Formula composition & Density $\left(\mathrm{g} \cdot \mathrm{cm}^{-3}\right)$ \\
\hline 1 & Modeling powder & ZY-1 & $\mathrm{HMX} / \mathrm{Al} /$ others & 0.77 \\
\hline 2 & Modeling powder & ZY-2 & $\mathrm{RDX} / \mathrm{Al} /$ others & 0.85 \\
\hline 3 & Press & TNT & TNT & 1.57 \\
\hline 4 & Pouring & ZY-4 & $\mathrm{HMX} / \mathrm{Al} /$ others & 1.81 \\
\hline 5 & Casting & ZY-5 & $\mathrm{RDX} / \mathrm{Al} /$ others & 1.87 \\
\hline
\end{tabular}

Under the same ignition conditions, the combustion phenomena of explosives with different formulation systems are quite different. The current experimental results cannot find out the law of change. It is worth noting that the exposed part of ZY-4 explosive burns completely after 
ignition and the flame gradually goes out at the mouth of the measuring cylinder, which shows that the explosives of this formulation system cannot self-support combustion under the condition of hypoxia, which is conducive to the design of insensitive explosives. If the explosive ignites in the closed and anoxic condition, but the ignition energy is weak, the explosive which cannot self-support combustion can be controlled until it is extinguished by conduction and heat absorption. Table 3 shows the burning rate of common explosives. The comparison shows that the experimental results and literature results are at the same level.

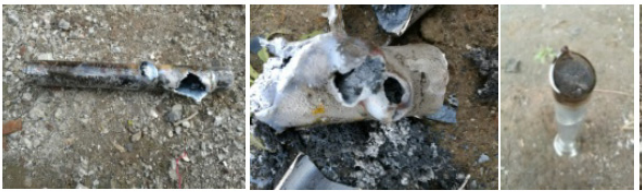

ZY-1

$\mathrm{ZY}-2$

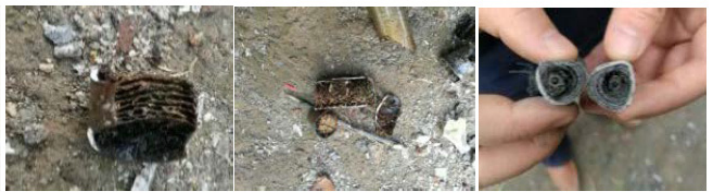

ZY-4

Fig. 2. Combustion products

The combustion products of ZY-4 explosive were collected and the morphology of the products was observed by SEM. Take 200 times, and 1000 times photos for comparison. See Fig. 3 and Fig. 4 for the results. The combustion products show a space network structure, with non-reactive molten substances attached. HMX crystal particles and alumina particles can be seen on the burning out section. The network structure formed by the binder and combustion products may play a role in flame retardant, resulting in the failure of self-sustaining combustion of explosives under the condition of hypoxia.

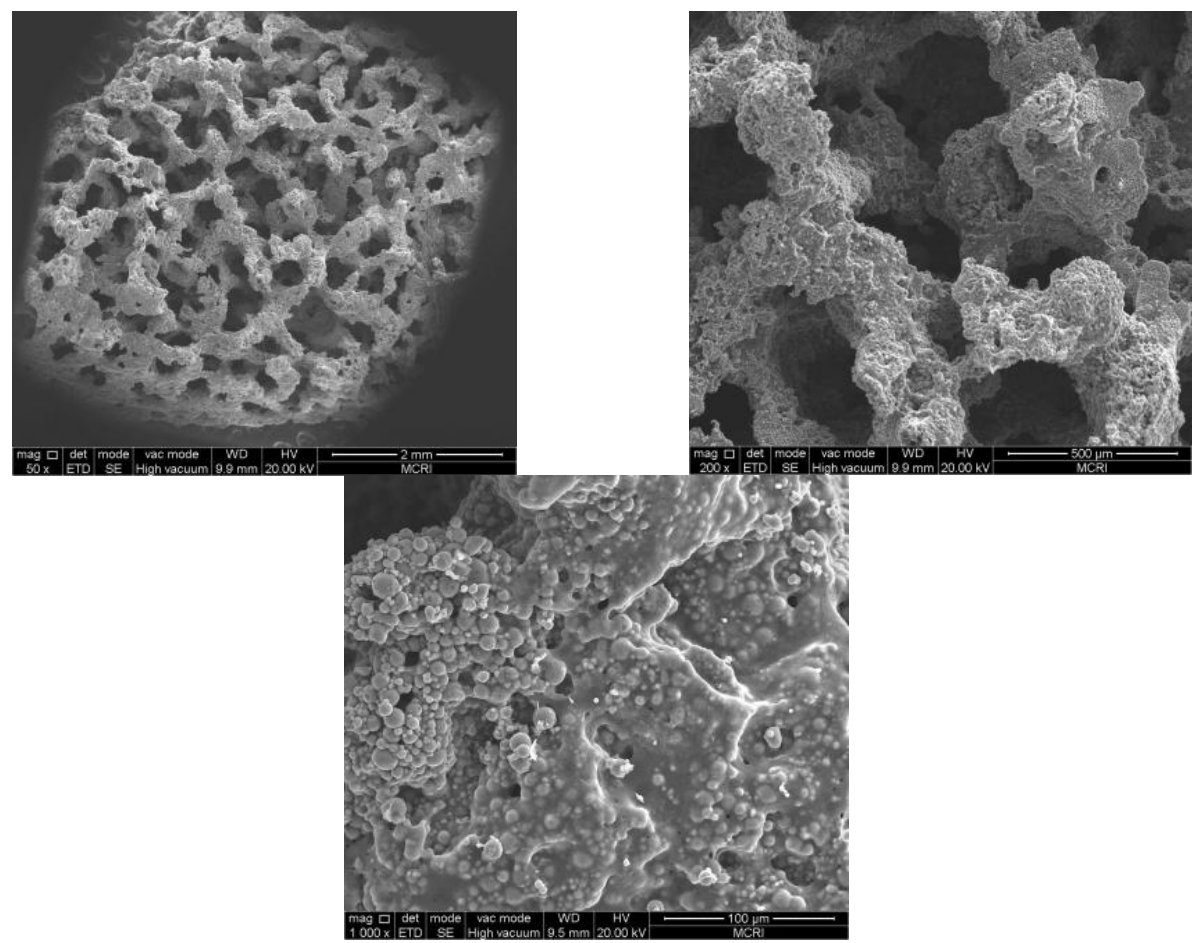

Fig. 3. Combustion products

\subsection{Effect of porosity change on explosive combustion}

The sample is ZY-1 molding powder, the $100 \mathrm{ml}$ volumetric cylinder is selected as the 
container, and the explosive volume is controlled as $100 \mathrm{ml}$ (the diameter of the cylinder is $30 \mathrm{~mm}$ ). The density is changed by manual compaction, and the explosive density is calculated after weighing. See Table 4 for sample parameters.

Table 2. Test results

\begin{tabular}{|c|c|c|c|c|}
\hline No. & Explosives & $\begin{array}{c}\text { Reaction rate } \\
/ \mathrm{mm} \cdot \mathrm{s}^{-1}\end{array}$ & Combustion phenomenon & $\begin{array}{c}\text { Reaction } \\
\text { intensity }\end{array}$ \\
\hline 1 & $\mathrm{ZY}-1$ & 4.0 & $\begin{array}{c}\text { Fast combustion, loud sound, large amount of } \\
\text { metal combustion sparks can be seen }\end{array}$ & Combustion \\
\hline 2 & $\mathrm{ZY}-2$ & 0.49 & $\begin{array}{c}\text { The combustion is slow and stable. There is no } \\
\text { visible flame on the combustion array, and the } \\
\text { visible flame is stable }\end{array}$ & Combustion \\
\hline 3 & $\mathrm{TNT}$ & 2.1 & $\begin{array}{c}\text { Combustion is unstable and combustion } \\
\text { products are black and viscous }\end{array}$ & Combustion \\
\hline 4 & $\mathrm{ZY}-4$ & $\sim 1.1$ & $\begin{array}{c}\text { The exposed part burns completely, and the } \\
\text { flame goes out gradually at the mouth of the } \\
\text { measuring cylinder }\end{array}$ & Extinguish \\
\hline 5 & ZY-5 & 0.30 & $\begin{array}{c}\text { Mild combustion, no spark, no open fire on the } \\
\text { combustion surface, flame at the mouth of glass } \\
\text { pipe, and basically stable burning rate }\end{array}$ & $\begin{array}{c}\text { Flameless } \\
\text { combustion }\end{array}$ \\
\hline
\end{tabular}

Table 3. Relationship between density and reaction rate of Tetryl and RDX (charge diameter $24 \mathrm{~mm}$ )

\begin{tabular}{|c|c|}
\hline Density $\left(\mathrm{g} \cdot \mathrm{cm}^{-3}\right)$ & $\begin{array}{llllllll}0.68 & 0.69 & 0.74 & 0.85 & 1.04 & 1.05 & 1.07 & 1.16\end{array}$ \\
\hline Combustion rate of Tetryl $\left(\mathrm{cm} \cdot \mathrm{min}^{-1}\right)$ & $\begin{array}{llll}5.41 & 4.83 & 4.46 & 4.27\end{array}$ \\
\hline Combustion rate of RDX $\left(\mathrm{cm} \cdot \mathrm{min}^{-1}\right)$ & $\begin{array}{llll}3.46 & 3.19 & 2.19 & 1.49\end{array}$ \\
\hline
\end{tabular}

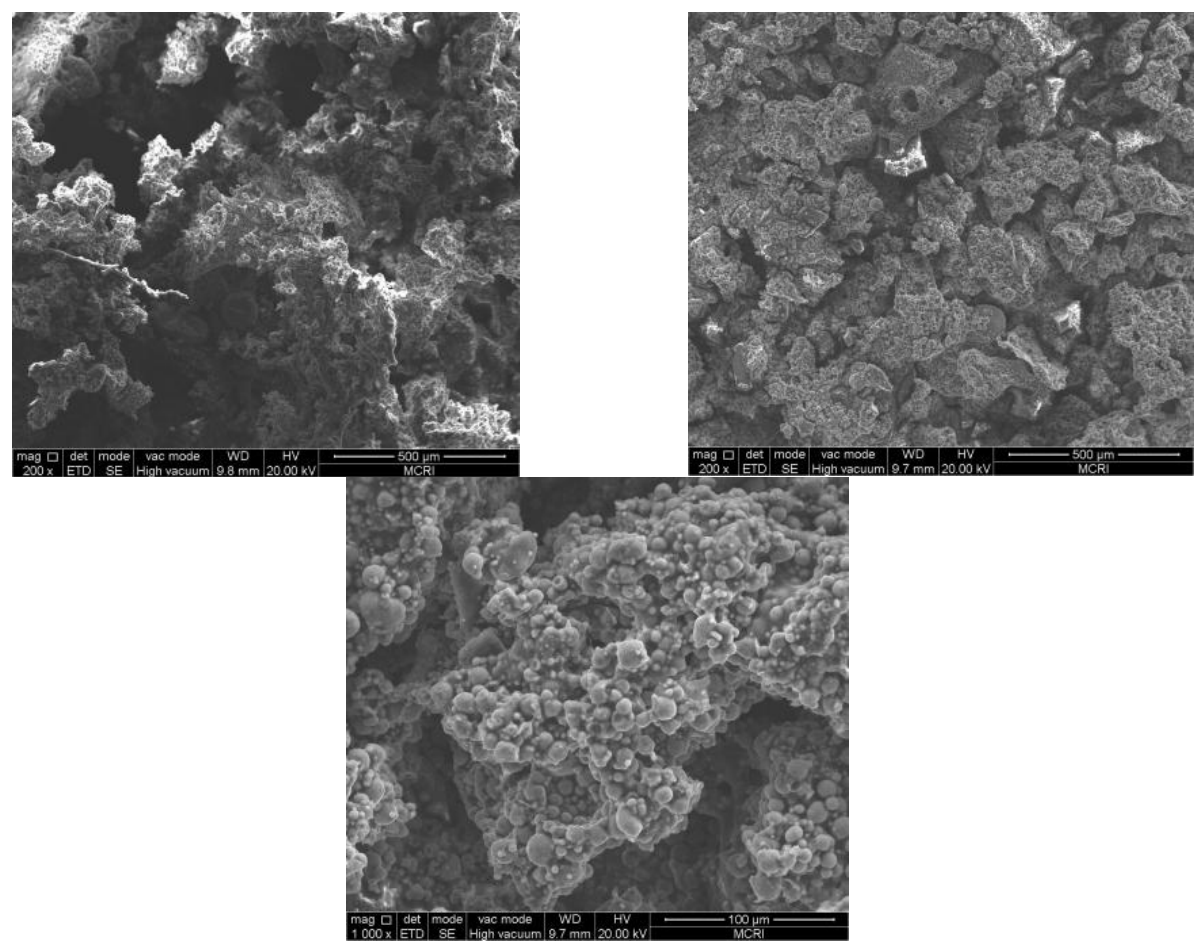

Fig. 4. Burning out section of PBX

Scatter plot is drawn with density as abscissa and reaction propagation rate as ordinate, Use the least square method to fit the data points linearly, as shown in Fig. 5, the calculation formula 
of reaction propagation rate of ZY-1 explosive after non-impact ignition is obtained:

$V_{\text {reaction }}=5.5-2.07 \times \rho$,

where $\rho$ is the explosive charge density, unit, $\mathrm{g} \cdot \mathrm{cm}^{-3}$.

Table 4. Sample parameters

\begin{tabular}{|c|c|c|c|}
\hline No. & Mass / g & Density $\left(\mathrm{g} \cdot \mathrm{cm}^{-3}\right)$ & Reaction rate $/ \mathrm{mm} \cdot \mathrm{s}^{-1}$ \\
\hline 1 & 71 & 0.71 & 4.1 \\
\hline 2 & 74 & 0.74 & 3.9 \\
\hline 3 & 78 & 0.78 & 4.0 \\
\hline 4 & 91 & 0.91 & 3.5 \\
\hline 5 & 105 & 1.05 & 3.4 \\
\hline 6 & 117 & 1.17 & 3.1 \\
\hline
\end{tabular}

The sample with density of $0.80 \mathrm{~g} \cdot \mathrm{cm}^{-3}$ is used for the verification experiment. The measured reaction propagation rate is $3.9 \mathrm{~mm} \cdot \mathrm{s}^{-1}$, the calculated result of Eq. (2) is $V_{\text {reaction }}=3.8 \mathrm{~mm} \cdot \mathrm{s}^{-1}$, and the calculated relative error is $3 \%$, which meets the technical requirements.

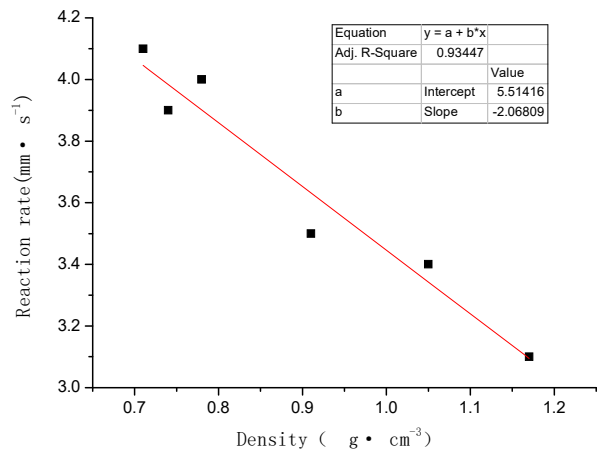

Fig. 5. Effect of density (porosity) change on reaction rate of ZY-1 explosive

\section{Conclusions}

According to the characteristics of non-plasma in the reaction zone of explosive combustion, the device and method for the study of the reaction growth characteristics of explosive after non-impact ignition are established, and the effects of explosive forming process and porosity change on the reaction growth after ignition are studied. According to the study of ZY-5 explosive, the change of composition of explosive can significantly affect the combustion state of explosive; the microstructure of combustion products is studied by SEM, and it is considered that the bonding of HTPB system and combustion products used in pouring explosive can build a space network with flame retardant function, which has a good inhibiting effect on the flame, and can be used for new insensitive melting casting and pouring explosive.

\section{References}

[1] Leiber C. O. Assessment of Safety and Risk with a Microscopic Model of Detonation. Elsevier, 2003.

[2] Graham R. A., Cberet R., Eden F. G., et al. High-Pressure Shock Compression of Condensed Matter. Springer-Verlag, New York, 1995.

[3] DOE Explosives Safety Manual. Manual DOE 440.1-1A, 2006.

[4] Tarver C. M., Chidester S. K. On the violence of high explosive reactions. Journal of Pressure Vessel Technology, Vol. 127, Issue 1, 2005, p. 39-48.

[5] Asay B. W. Shock Wave Science and Technology Reference Library (Volume 5): Non-Shock Initiation of Explosives. Springer, Berlin, 2010. 
[6] Maienschein J. L., Wardell J. F. Deflagration behavior of PBXN-109 and composition B at high pressures and temperatures. Joint Army Navy NASA Air Force 38th Combustion Subcommittee, 2003.

[7] Ctirdaneli S., Ak M. A., Ulas A. Experimental analysis on the measurement of ballistic properties of solid propellants. Flame Structure, Vol. 39, Issue 3, 2007, p. 032103.

[8] Timms R., Purvis R., Curtis J. P. A mechanism for hot-spot generation in a reactive two-dimensional sheared viscous layer. Combustion Theory and Modelling, Vol. 22, Issue 3, 2018, p. 554-584.

[9] Arora H., Tarleton E., Li Mayer J., et al. Modelling the damage and deformation process in a plastic bonded explosive microstructure under tension using the finite element method. Computational Materials Science, Vol. 110, 2015, p. 91-101.

[10] Shang Hailin, Yang Jie, Zhao Feng, et al. Experimental study on ignition and combustion of HMX particle explosive under low velocity impact. Modern Applied Physics, Vol. 8, Issues 2, 2017, p. $71-82$.

[11] Wu Yanqing, Baoxiaowei, Wang Mingyang, et al. Ignition combustion mechanism of RDX/HMX particle explosives by drop impact. Explosion and Impact, Vol. 37, Issue 2, 2017, p. 339-346. 